\title{
Extraction of Phytosterol Concentration in Different Legume Pods by Using Microwave-Assisted Hydrodistillation
}

\author{
Noormazlinah $^{1, *}$, Norlaili Hashim ${ }^{1}$, Abdurahman Hamid Nour ${ }^{1}$, Mimi Sakinah Abdul Munaim ${ }^{2}$, \\ Maria Pilar Almajano ${ }^{3}$, and Nurul Bahirah ${ }^{1}$
}

${ }^{1}$ Faculty of Chemical and Natural Resources Engineering, Universiti Malaysia Pahang,

Lebuhraya Tun Razak, 26300 Gambang, Pahang, Malaysia

${ }^{2}$ Faculty of Engineering Technology, Universiti Malaysia Pahang, Pahang, Malaysia, Lebuhraya Tun Razak, 26300 Gambang, Pahang, Malaysia

${ }^{3}$ Department of Chemical Engineering, Technical University of Catalonia, Avigunda Diagonal 647, Barcelona 08028, Spain

\section{* Corresponding author:}

tel: $+609-5492868$

email:mazlinah@umpedu.my

Received: August 3, 2018

Accepted: December 12, 2018

DOI: $10.22146 /$ ijc. 40865

\begin{abstract}
The traditional ways in the extraction of bioactive compounds using conventional methods are disadvantageous from both economic and environmental perspectives. In this, the potential of microwave-assisted hydrodistillation conditions for extraction of phytosterol from legume pods was investigated. Salkowski test performed on the legume pod has shown the reddish brown in all sample which confirmed the presence of phytosterol qualitatively. Liebermann-Burchard procedure and ultraviolet-visible spectroscopy (UV-Vis) apparatus were used to study the concentration of phytosterol at different extraction parameters which are temperature $\left(25-80^{\circ} \mathrm{C}\right)$, solvent concentration $(50-100 \% \mathrm{v} / \mathrm{v})$, irradiation time $(1-10 \mathrm{~min})$ and microwave power $(400-800 \mathrm{~W})$. The optimal conditions for highest yield of extract $(0.219 \mathrm{mg} / \mathrm{L})$ were obtained at a microwave power of $600 \mathrm{~W}$, the irradiation time of $6 \mathrm{~min}$, and ethanol concentration of $75 \% \mathrm{v} / \mathrm{v}$. Results obtained in this study have shown the capability of microwave-assisted hydrodistillation in the extraction of phytosterol from legume pod. Further works are nevertheless required to provide a deeper understanding of the mechanisms involved to facilitate the development of an optimum system applicable to the industry.
\end{abstract}

Keywords: phytosterol; microwave assisted extraction; one-factor-at-a-time; Salkowski test

\section{- INTRODUCTION}

Phytosteroid is one of many phytochemicals which is from the big family of phytosterol. Beta-sitosterol is the most abundant phytochemical to be found in the plant structure. In nature, phytosterols can present as the plant sterol that presents in the plant nonsaponifiable oils which has the same structure to cholesterol but with an addition of sterol chain at C24 position [1]. Beta-sitosterol has categorized as the plant-based phytosterol. Study deduce that beta-sitosterol comes with various pharmaceutical properties such as they inhibit the growth of colon and prostate cancer [2-3] and also controlling the carcinogenic property in the colon cancer cell [4]. Besides that, beta-sitosterol also has the properties of antidiabetic and antioxidant that are good in the high sugar blood condition [5].

Fruit peels and pods are usually being discarded, and only the flesh and the seeds of the fruit are consumed. The peels and the pods are considered as a waste as they do not have any beneficial side to the food taste and human health. The pod and peel of the legume usually considered as a waste. But there is a study that indicates that the chemical properties in the pod also has a beneficial effect. There was research present on the studies of the agro-waste that usually not been or fully utilized [6]. Even though the peel and pod are considered as a biodegradable material, but they also can

Noormazlinah et al. 
cause environmental issue [7]. The plant waste such as its legume pod, peel, and skin can be converted into a new product that can be utilized such as adaptable functional components or as natural active component [6].

The extraction process is an essential step to obtain the desired product from the plant. Generally, the extraction of phytosterol was done by using several types of extraction such as Liquid-Liquid Extraction, SolidPhase Extraction, Soxhlet Extraction, and MicrowaveAssisted Extraction [35]. However, several types of extraction process were less efficient in time management, usually used up the high volume of toxic organic solvents and also oppose with numerous step and process that may lead to losses of desired phytochemical [8]. The microwave-assisted extraction process is more efficient to produce a higher yield of phytochemical with less energy and time [9]. Besides that, by using microwave-assisted extraction method also could reduce the use of solvent extraction [10]. However, like the other method, the extraction yield is depending on the extraction parameter such as irradiation duration, temperature, power, solidliquid ratio and solvent concentration [11].

Thus, it is significant to study the method to extract phytochemical content in legume pod in order to obtain a higher yield in the extraction process. The extraction process that can be used is microwave-assisted extraction (MAE) of phytosterol. Lately, the MAE process gains significant exposure where the extraction process consists of microwave irradiation and organic solvent extraction, where it can efficiently perform the extraction phytochemical with lesser extraction time, a smaller amount of solvent usage and higher extraction yield of desired phytochemical [12].

Therefore, this research studies the usage of microwave-assisted hydrodistillation to extract phytosterol from legume pod. Thus, the aim of this study is to explore the effects of extraction parameter such as irradiation power, temperature, duration, and solvent concentration on the phytosterol concentration yield from the three legume pods.

\section{- EXPERIMENTAL SECTION}

\section{Chemical and Material}

The chemicals used were $95 \%$ ethanol $\mathrm{GmbH}, 1 \mathrm{M}$ sulphuric acid Merck and 98\% acetic anhydride. Methanol HPLC was obtained from Permula Chemical Sdn. Bhd., the ultrapure water was purified by Milli- ${ }^{\circ}$ Advantage A10 Purification System. Standard betasitosterol was purchased from Sigma Co., USA. Raw materials used in this study are Archindendron pauciflorum, Parkia speciosa, and Leucaena leucocephala legume pod. The plant sample obtained from Pekan district area.

\section{Procedure}

\section{Plant sample preparation}

After the samples were collected, it was prewashed by using distilled water and dried by using the paper towel. Then, the plant was ground by using Panasonic MXAC210SW blender to increase the surface area to contact with the solvent [13]. After that, the plant sample was stored at $-20^{\circ} \mathrm{C}$.

\section{Extraction process}

The extraction process was conducted by using the microwave-assisted hydrodistillation (MAH) extraction unit. The ratio of plant sample's weight and solvent volume was $1 / 20$ [28]. The extraction process was repeated by using several desired parameters such as extraction solvent concentration, the temperature of the extraction process, duration of the extraction process and the microwave irradiation power. After the extraction process, the liquid sample was reduced its volume to $1 / 4$ from the original volume by using rotary evaporator. The sample was then stored at $-4{ }^{\circ} \mathrm{C}$ for further analysis.

Table 1. Extraction parameter range

\begin{tabular}{ll}
\hline Extraction Parameter & Parameter range \\
\hline Ethanol concentration $(\%)$ & $45-95$ \\
Temperature $\left({ }^{\circ} \mathrm{C}\right)$ & $25-80$ \\
Time (Duration) (min) & $1-10$ \\
Power (W) & $200-800$ \\
\hline
\end{tabular}




\section{Salkowski test}

Concentrated extracted sample was measured for $1 \mathrm{~mL}$ and was added into $5 \mathrm{~mL}$ of chloroform. After that, a few drops of concentrated sulphuric acid was added to the extracted solution. The presence of steroid was indicated by the forming of a reddish brown color in the upper layer solution [14].

\section{Liebermann-Burchard reagent}

Fifty milliliters of acetic anhydride was transferred into an amber vial and left in an ice bath for $30 \mathrm{~min}$. After that, $5 \mathrm{~mL}$ of sulphuric acid was added carefully into the ice-cold acetic anhydride.

\section{Beta-sitosterol calibration curve}

The standard of Beta-sitosterol was diluted at a different concentration range from 0.02 to $0.10 \mathrm{mg} / \mathrm{mL}$ to generate the calibration curve. From the data obtained, the calibration curve was plotted where the calibration equation was calibrated. The calibration equation was shown below.

$\mathrm{y}=\mathrm{mx}+\mathrm{c}$

where, $\mathrm{y}=$ absorbance value; $\mathrm{m}=\mathrm{s}$ lope of the graph (6.3117); $c=$ constant value $(0.0124)$

\section{Sample quantitative analysis}

After that, $1 \mathrm{~mL}$ of reduced volume sample was added with $20 \mathrm{~mL}$ of chloroform and added up to $50 \mathrm{~mL}$ with the ethanolic water solvent. Then, $5 \mathrm{~mL}$ of the sample was transferred into $10 \mathrm{~mL}$ volumetric flasks and added with $2 \mathrm{~mL}$ of Liebermann-Burchard reagent. The solution volume was adjusted with chloroform. The absorption of the sample was measured by using UV/Vis after $5 \mathrm{~min}$ addition of Liebermann-Burchard reagent. Chloroform

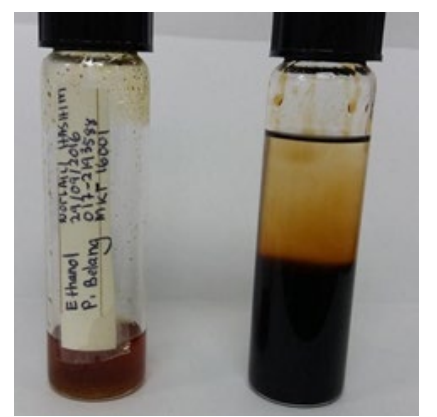

Fig 2. Salkowski test on L. leucocephala was used as the measured blank. The method for quantitative analysis was supported by another study by Araujo et al. [15].

\section{- RESULTS AND DISCUSSION}

\section{Salkowski Test}

Salkowski test is a type of qualitative analysis to test the presence of steroid in the extracted sample. The steroid was present as the reddish color appeared on the upper layer of chloroform [13]. From all three samples tested, all were positively tested with the steroid.

Fig. 1 shows the presence of steroid in Archindendron jiringa legume pod extract. A recent study demonstrates the presence of steroid and triterpenoid in the $70 \%$ of ethanolic extract of A. pauciflorum legume pod [21]. Besides that, Fig. 2 also detected the presence of steroid in L. leucocephala legume pod extract. The $L$. leucocephala plant sample had tested positive with steroid as referring to several other pieces of research [16]. From studies perform by Arun et al. shows the evidence that the slightly present of sterol in hexane and methanol extract of L. leucocephala [17]. Lastly, Fig. 3 also

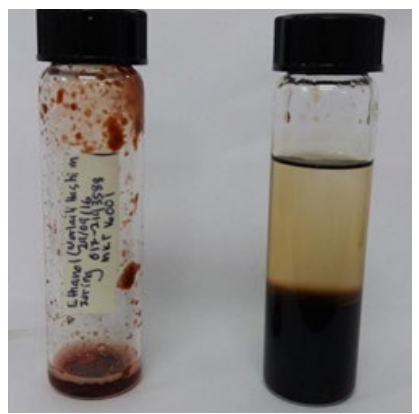

Fig 1. Salkowski test on A. jiringa

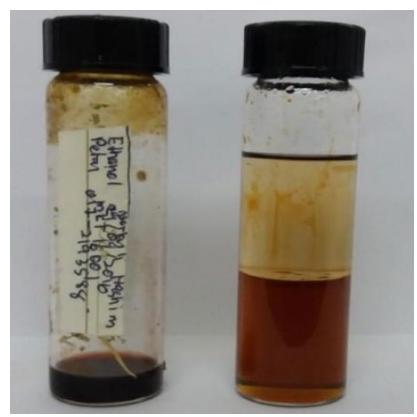

Fig 3. Salkowski test on P. speciose 
generated the present of steroid in P. speciosa legume pod extract. Previous studies also derive the presence of steroid in the ethanolic extracted solution from P. speciosa [18].

\section{Liebermann-Burchard UV-Vis Analysis}

After the addition of chloroform, sulfuric acid, and acetic anhydride into the extracted plant sample, the sample solution was turned to violet-blue then formed green color manifested the present of steroids [13]. The first process occurs in the solution is the protonated of the phytosterol then followed by the loss of $\mathrm{H}_{2} \mathrm{O}$ or dehydration process where carbonium ion of 3,5cholestadiene was formed [19]. Then, the oxidation process occurs where the blue color is formed from the pentacyclic cations [20]. The wavelength to be used in the analysis was set at $625 \mathrm{~nm}$ as blue oxidation process was maximum occurs at $625 \mathrm{~nm}$ [14]. In Fig. 4 manifested the calibration curve calibrate from the beta-sitosterol standard. The result of the beta-sitosterol concentration present in the plant sample was shown in Fig. 5 to 8.

\section{Effect of Solvent Concentration}

In this research, ethanol was used as the extraction solvent. There was plenty of reason for the use of ethanol as it is toxic free, safe to the environment and mostly use extraction solvent for extracting natural based product [21-22]. Besides that, ethanol also can dissolve the desired compound and also has a great polarity for the microwave to absorb the desired compound [23]. The ethanol mixed

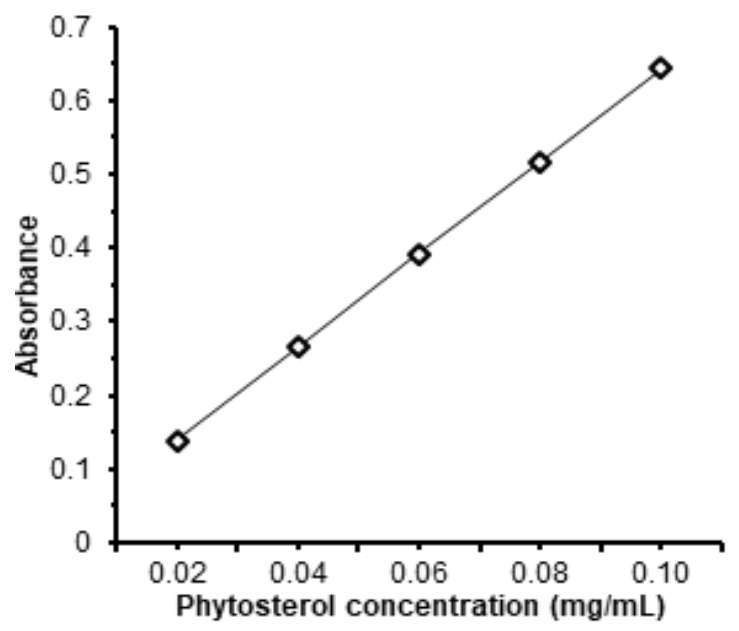

Fig 4. Calibration curve of beta-sitosterol (phytosterol) standard absorption with water was used. Ethanol has a lower polarity so that allowing the solubility of beta-sitosterol to increase in the extraction solvent [24]. The mixture of ethanol with water allows the heating process of the microwave to be improved because of water high dielectric constant [25]. Besides that, water also enhances the penetrability of plant matrices to increase the mass transfer process and the diffusion of desired phytochemical [26]. Another condition was fixed at the temperature of $75{ }^{\circ} \mathrm{C}$, three cycles at a duration of $6 \mathrm{~min}$ per cycle and irradiation power of $600 \mathrm{~W}$.

Different concentration of ethanol gave different result in the phytosteroid extracted concentration content. The concentration of beta-sitosterol in $L$. leucocephala has the highest value followed by $A$. pauciflorum and then $P$. speciosa with the lowest value of $0.2191,0.0313$, and $0.1101 \mathrm{mg} / \mathrm{mL}$, respectively. The yield produced increased as the increase of the concentration of the ethanol and gained the maximum yield at the concentration of $75 \%$ and drop after the concentration above $75 \%$ in all plant legume sample.

Phytosteroid has the properties of hydrophobic. The fat-soluble phytosteroid is favorably extracted in the high ethanol concentration. But, water-soluble phytosteroid is more beneficially extracted in low ethanol concentration. So, based on the research result, the most suitable ethanol concentration was $75 \%$. This was supported by the result obtained from the extraction

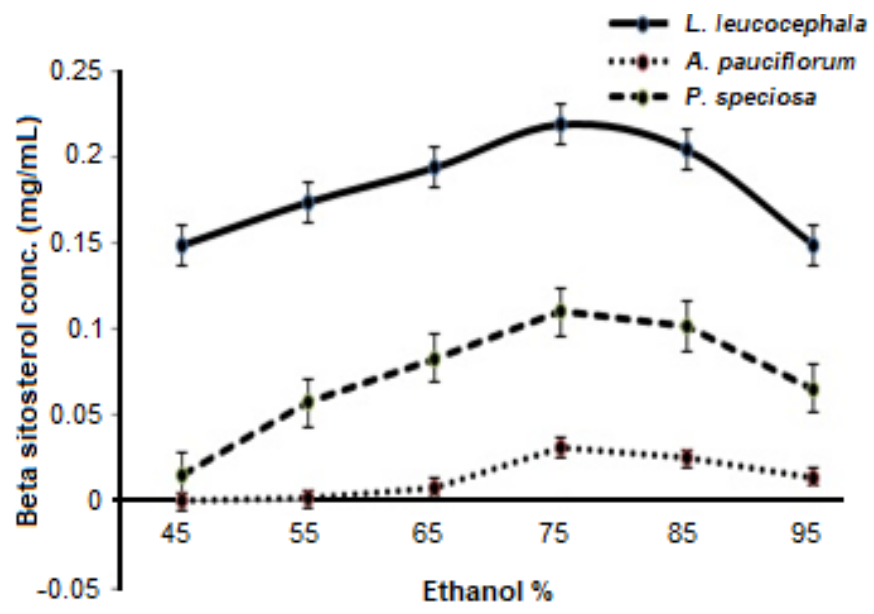

Fig 5. The concentration of beta sitosterol present at a different ethanol concentration 
of steroid saponin from Dioscorea zingiberensis Wright [27]. Fig. 5 shows the legumes concentration at different ethanol extraction solvent concentration.

\section{The Temperature of the Extraction Process}

The temperature of the extraction process varied from 25 to $80{ }^{\circ} \mathrm{C}$. Another condition was fixed at three cycles at a duration of $6 \mathrm{~min}$ per cycle, ethanol concentration at $75 \%$ and irradiation power of $600 \mathrm{~W}$. In common, the suitable temperature will result in better solute solubility in the extraction solution. Temperature also a factor that is correlated with irradiation power where it controls the amount of energy transformed into heat in the dielectric material [28]. The concentration of beta-sitosterol in L. leucocephala was the highest among the other two plant legume, A. pauciflorum and $P$. speciose, which was $0.2067,0.0828$, and $0.1091 \mathrm{mg} / \mathrm{mL}$, respectively. As for the result of the phytosteroid yield, the yield increase as the temperature increase from 50 to $75{ }^{\circ} \mathrm{C}$. This was because of the increase of the diffusion coefficient of the extraction solvent when the viscosity of the solvent decreased within the temperature range that would assist the efficiency of the microwave-assisted extraction process. As the temperature increase above the optimum temperature of $75{ }^{\circ} \mathrm{C}$, the beta-sitosterol concentration decreased might be caused of the extraction of the non-phytosterol component that may occur and increase in volume making a dilution of beta-sitosterol in the extracted solution [29]. This may because the high temperature partially causes the phytosteroid to damage and reduced. So, the most suitable temperature to be set for the microwave-assisted extraction process was $75^{\circ} \mathrm{C}$.

Theoretically, the plant tissue will be softened at high temperature and then alter the cell membrane of the plant cell [30] that is resulting in the extraction process of the phenolic compound to be done easier [31]. But, a longer time in the extraction process may cause the oxidation and degradation of the desired product from the plant [32]. Studies assumed that phenolic compound is very sensitive to any heat process and can easily be oxidized. This deduces that the maximum temperature of the extraction process must be controlled at all-time [33].

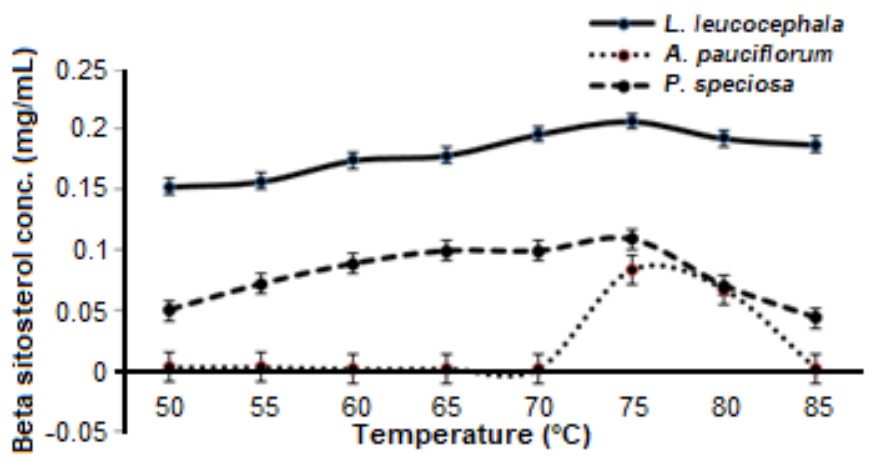

Fig 6. represents the legumes concentration at different microwave irradiation temperature.

\section{Duration of the Extraction Process}

As for the microwave-assisted extraction process, it saves a lot of time as compared to another conventional method. As time has been reduced, the cost in product process will also be reduced. The longer the duration of the extraction, the longer time of compound to be exposed to the irradiation power. The excess exposure to the irradiation power may lead to the loss of desired phytochemical [28]. Besides that, the longer duration of the extraction process may lead to another unwanted reaction such as enzymatic degradation and oxidation and may cause the desired yield compound to reduce [33]. The extraction process is mainly depended on time and temperature if the irradiation. As the temperature and duration of the extraction process are increased, the product yield of the desired compound also increase, but the elongated duration of extraction process may result in the deficit thermolabile bioactive compounds [34]. The duration of the extraction process varied from 1 to $10 \mathrm{~min}$. Another condition was fixed at the temperature of $75^{\circ} \mathrm{C}$, ethanol concentration at $75 \%$ and irradiation power of $600 \mathrm{~W}$.

The concentration of beta-sitosterol was found highest in L. leucocephala, followed by A. pauciflorum, then $P$. speciosa which was $0.2037,0.0858$, and $0.1075 \mathrm{mg} / \mathrm{mL}$, respectively. As the extraction process time increased to $6 \mathrm{~min}$, the yield of phytosteroid also increased. But, as the time increased to longer duration, the yield reduced. Elongated duration exposed to the 


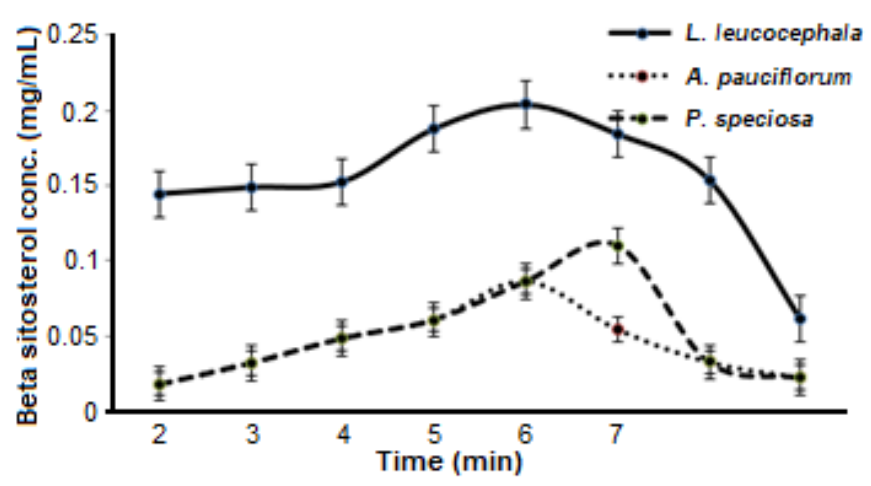

Fig 7. The concentration of beta-sitosterol present at different extraction duration

microwave irradiation may cause the phytosteroid degraded into another substance other than phytosteroid as the exposure duration to oxygen is longer [32]. Therefore, the most suitable duration for the extraction process was $6 \mathrm{~min}$. Fig. 7 generated the legumes concentration at different microwave irradiation duration.

\section{Microwave Irradiation Power}

In the extraction process, the irradiation power also plays a part in extracting the desired phytochemical from the plant structure by breaking the cell wall and also altering equilibrium and mass transfer condition in the extraction process [35]. The time and power of the radiation are two factors, but they were interconnected to each other. The most suitable approach for power and time is as a combination of lower power with longer radiation time expose to the extracted material [31]. The irradiation power of the extraction process varied from 100 to $800 \mathrm{~W}$. Another condition was fixed at the temperature of $75{ }^{\circ} \mathrm{C}$, ethanol concentration at $75 \%$ and three cycles at a duration of 6 min per cycle. Based on the result, it evidences that the phytosteroid yield increased as the power of irradiation increased. The concentration of beta-sitosterol in L. leucocephala was detected as the highest value, while $A$. pauciflorum had the second highest value followed by $P$. speciosa which had the lowest beta-sitosterol concentration for $0.2070,0.0725$, and $0.1085 \mathrm{mg} / \mathrm{mL}$, respectively. As the irradiation power increased, the molecular interaction between the substance in the sample would distress leading to the reduction of the phytosteroid yield. It may also damage the

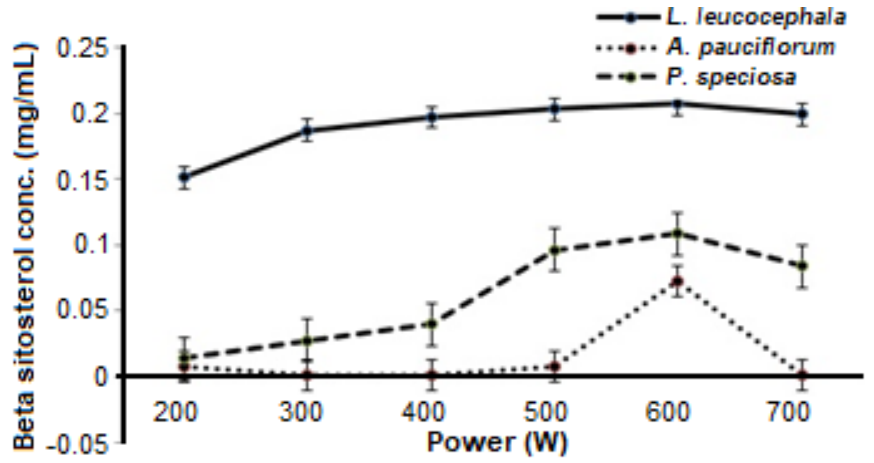

Fig 8. The concentration of beta-sitosterol present at different extraction power

phytosteroid content in the sample. So, the most suitable irradiation power for the extraction process was $600 \mathrm{~W}$. Fig. 8 surfaced the legumes concentration at different microwave irradiation power.

\section{- CONCLUSION}

Based from the solvent concentration studies, the concentration of phytosterol contain in the $L$. leucocephala $(0.2191 \mathrm{mg} / \mathrm{mL})$ was the highest compared to the content of phytosteroid in A. pauciflaurum $(0.0313 \mathrm{mg} / \mathrm{mL})$ and P. speciosa $(0.1101 \mathrm{mg} / \mathrm{mL})$. From this study, it showed that the most optimum condition for the extraction process of beta-sitosterol from legume pod was 6 min of irradiation duration using $600 \mathrm{~W}$ of irradiation power, $75 \%$ of solvent concentration and $75{ }^{\circ} \mathrm{C}$ irradiation temperature. The present of phytosteroid can be analyzed using the spectrometric principle, first done with the application of the Liebermann-Burchard test and then followed by the $\mathrm{UV}-\mathrm{V}$ is spectrometer analysis.

\section{- ACKNOWLEDGMENTS}

I would like to deeply thank to Universiti Malaysia Pahang and FKKSA for providing the opportunity and location for this study to take place. I sincerely apologize to all my colleagues who are relevantly helping me with this work. This study was fully sponsored by Universiti Malaysia Pahang under research grant of PGRS180336.

\section{- REFERENCES}

[1] Jones, P.J., and AbuMweis, S.S., 2009, Phytosterols as functional food ingredients: linkages to 
cardiovascular disease and cancer, Curr. Opin. Clin. Nutr. Metab. Care, 12 (2), 147-151.

[2] Awad, A.B., Chen, Y.C., Fink, C.S., and Hennessey, T., 1996, Beta-sitosterol inhibits HT-29 human colon cancer cell growth and alters membrane lipids, Anticancer Res., 16 (5A), 2797-2804.

[3] Yu, S., Hongkun, X., Chenghai, L., Chai, L., Xiaolin, S., and Xianzhe, Z., 2016, Comparison of microwave assisted extraction with hot reflux extraction in acquirement and degradation of anthocyanin from powdered blueberry, Int. J. Agric. Biol. Eng., 9 (6), 186-100.

[4] Baskar, A.A., Ignacimuthu, S., Paulraj, G.M., and AlNumair, K.S., 2010, Chemopreventive potential of beta-sitosterol in experimental colon cancer model An in vitro and in vivo Study, BMC Complement. Altern. Med., 10, 24.

[5] Gupta, R., Sharma, A.K., Dobhal, M.P., Sharma, M.C., and Gupta, R.S., 2011, Antidiabetic and antioxidant potential of $\beta$-sitosterol in streptozotocin-induced experimental hyperglycemia, J. Diabetes, 3 (1), 29-37.

[6] Gan, C.Y., Manaf, N.A., and Latiff, A.A., 2010, Optimization of alcohol insoluble polysaccharides (AIPS) extraction from the Parkia speciosa pod using response surface methodology (RSM), Carbohydr. Polym., 79 (4), 825-831.

[7] Gan, C.Y., and Latiff, A.A., 2011, Antioxidant Parkia speciosa pod powder as potential functional flour in food application: Physicochemical properties' characterization, Food Hydrocolloids, 25 (5), 11741180 .

[8] Sulaiman, I.S.C., Basri, M., Masoumi, H.R.F., Chee, W.J., Ashari, S.E., and Ismail, M., 2017, Effects of temperature, time, and solvent ratio on the extraction of phenolic compounds and the antiradical activity of Clinacanthus nutans Lindau leaves by response surface methodology, Chem. Cent. J., 11 (1), 54 .

[9] Chan, C.H., Yusoff, R., Ngoh, G.C., and Kung, F.W., 2011, Microwave-assisted extractions of active ingredients from plants, J. Chromatogr. A, 1218 (37), 6213-6225.
[10] Garofulić, I.E., Dragović-Uzelac, V., Jambrak, A.R., and Jukić, M., 2013, The effect of microwaveassisted extraction on the isolation of anthocyanins and phenolic acids from sour cherry Marasca (Prunus cerasus var. Marasca), J. Food Eng., 117 (4), 437-442.

[11] Deo, S., Janghel, A., Raut, P., Bhosle, D., Verma, C., Kumar, S.S., Agrawal, M., Amit, N., Sharma, M., Giri, T., Tripathi, D.K., Ajazuddin, Alexander, A., 2015, Emerging microwave-assisted extraction (MAE) techniques as an innovative green technologies for the effective extraction of the active phytopharmaceuticals, Res. J. Pharm. Technol., 8 (5), 655-666.

[12] Xiao, W., Han, L., and Shi, B., 2008, Microwaveassisted extraction of flavonoids from Radix astragali, Sep. Purif. Technol., 62 (3), 614-618.

[13] Zygmunt, B., and Namieśnik, J., 2003, Preparation of samples of plant material for chromatographic analysis, J. Chromatogr. Sci., 41 (3), 109-116.

[14] Harborne, J.B., 1998, Phytochemical Methods: A Guide to Modern Technique of Plants Analysis, $3^{\text {rd }}$ ed., Chapman and Hall, London, 129-138, 302.

[15] Araújo, L.B.D.C., Silva, S.L., Galvão, M.A.M., Ferreira, M.R.A., Araújo, E.L., Randau, K.P., and Soares, L.A.L., 2013, Total phytosterol content in drug materials and extracts from roots of Acanthospermum hispidium by UV-VIS spectrophotometry, Rev. Bras. Farmacogn., 23 (5), 736-742.

[16] Rizal, M., Yusransyah, Y., and Stiani, S.N., 2016, Uji aktivitas antidiare ekstrak etanol $70 \%$ kulit buah jengkol (Archidendron pauciflorum (Benth.) I.C.Nielsen) terhadap mencit jantan yang diinduksi Oleum ricini, Jurnal Ilmiah Manuntung, 2 (2), 131136.

[17] Shantabi, L., Jagetia, G.C., Vabeiryureilai, M., Lalrinzuali K., 2014, Phytochemical screening of certain medicinal plants of Mizoram, India and their folklore use, J. Biodivers. Bioprospect. Dev., 2 (1), 136.

[18] Satyadev, A., Murthy, V., and Saroja, R., 2015, Phytochemical screening and antitubercular 
efficacy of leaf extracts of Leucaena leucocephala, IAJPR, 5 (3), 1023-1029.

[19] Ko, H.J., Ang, L.H., and Ng, L.T., 2013, Antioxidant activities and polyphenolic constituents of bitter bean Parkia speciosa, Int. J. Food Prop., 17 (9), 1977-1986.

[20] Wei, D., Wang, L., Liu, C., and Wang. B., 2010, $\beta$ sitosterol solubility in selected organic solvents, $J$. Chem. Eng. Data, 55 (8), 2917-2919.

[21] Brieskorn, C.H., and Hofmann, H., 1964, Beitrag zum chemismus der farbreaktion nach LiebermannBurchard, Arch. Pharm., 297, 577-588.

[22] Hemwimon, S., Pavasant, P., and Shotipruk, A., 2007, Microwave-assisted extraction of antioxidative anthraquinones from roots of Morinda citrifolia, Sep. Purif. Technol., 54 (1), 44-50.

[23] Oliveira, C., Nasr, A., Brindle, M., and Wales, P.W., 2012, Ethanol locks to prevent catheter-related bloodstream infections in parenteral nutrition: A meta-analysis, Pediatrics, 129 (2), 318-329.

[24] Wang, L., and Weller, C.L., 2006, Recent advances in extraction of nutraceuticals from plants, Trends Food Sci Technol., 17 (6), 300-312.

[25] von Holtz, R.L., Fink, C.S., and Awad, A.B., 1998, $\beta$ Sitosterol activates the sphingomyelin cycle and induces apoptosis in LNCaP human prostate cancer cells, Nutr. Cancer, 32 (1), 8-12.

[26] Sato, T., and Buchner, R., 2004, Dielectric relaxation processes in ethanol/water mixtures, J. Phys. Chem. A, 108 (23), 5007-5015.

[27] Boeing, J.S., Barizão, É.O., e Silva, B.C., Montanher, P.F., de Cinque Almeida, V., and Visentainer, J.V., 2014, Evaluation of solvent effect on the extraction of phenolic compounds and antioxidant capacities from the berries: Application of principal component analysis, Chem. Cent. J., 8 (1), 48.

[28] Ren, Y., Chen, Y., Hu, B., Wu, H., Lai, F., and Li, X., 2015, Microwave-assisted extraction and a new determination method for total steroid saponins from Dioscorea zingiberensis C.H. Wright, Steroids, $104,145-152$.
[29] Lovrić, V., Putnik, P., Kovačević, D.B., Jukić, M., and Dragović-Uzelac, V., 2017, Effect of microwave-assisted extraction on the phenolic compounds and antioxidant capacity of blackthorn flowers, Food Technol. Biotechnol., 55 (2), 243-250.

[30] Dunford, N.T., Irmak, S., and Jonnala, R., 2009, Effect of the solvent type and temperature on phytosterol contents and composition of wheat straw, bran, and germ extract, J. Agric. Food Chem., 57 (22), 10608-10611.

[31] Salomon, S., Sevilla, I., Betancourt, R., Romero, A., Nuevas-Paz, L., and Acosta-Esquijarosa, J., 2014, Extraction of mangiferin from Mangifera indica $\mathrm{L}$. leaves using microwave-assisted technique, Emir. J. Food Agric., 26 (7), 616-622.

[32] Shi, J., Yu, J., Pohorly, J.E., and Kakuda, Y., 2003, Polyphenolics in grape seeds-biochemistry and functionality, J. Med. Food, 6 (4), 291-299.

[33] Chirinos, R., Rogez, H., Campos, D., Pedreschi, R., and Larondelle, Y., 2007, Optimization of extraction conditions of antioxidant phenolic compounds from mashua (Tropaeolum tuberosum Ruíz and Pavón) tubers, Sep. Purif. Technol., 55 (2), 217-225.

[34] Khoddami, A., Wilkes, M.A., and Roberts, T.H., 2013, Techniques for analysis of plant phenolic compounds, Molecules, 18 (2), 2328-2375.

[35] Uddin, M.S., Sarker, M.Z., Ferdosh, S., Akanda, M.J., Easmin, M.S., Shamsudina, S.H., and Bin Yunus, K., 2015, Phytosterols and their extraction from various plant matrices using supercritical carbon dioxide: A review, J. Sci. Food Agric., 95 (7), 1385-1394.

[36] Ghasemzadeh, A., Jaafar, H.Z.E., Rahmat, A., and Swamy, M.K., 2017, Optimization of microwaveassisted extraction of zerumbone from Zingiber zerumbet L. rhizome and evaluation of antiproliferative activity of optimized extracts, Chem. Cent. J., 11, 5. 